\title{
Oral delivery of Bacillus subtilis spores expressing Clonorchis sinensis paramyosin protects grass carp from cercaria infection
}

\author{
Hengchang Sun ${ }^{1,2,3,4} \cdot$ Mei Shang ${ }^{1,2,3,4} \cdot$ Zeli Tang $^{5} \cdot$ Hongye Jiang $^{2,3,4} \cdot$ Huimin Dong ${ }^{1}$. Xinyi Zhou ${ }^{2,3,4}$. \\ Zhipeng Lin $^{2,3,4}$. Cunbin Shi ${ }^{6}$ Pengli Ren ${ }^{2,3,4} \cdot$ Lu Zhao ${ }^{2,3,4} \cdot$ Mengchen Shi ${ }^{2,3,4} \cdot$ Lina Zhou ${ }^{2,3,4} \cdot$ Houjun Pan ${ }^{6}$. \\ Ouqin Chang ${ }^{6} \cdot$ Xuerong $\mathrm{Li}^{2,3,4} \cdot$ Yan Huang ${ }^{2,3,4}$ (D) Xinbing $\mathrm{Yu}^{2,3,4}$
}

Received: 24 September 2019 / Revised: 2 December 2019 / Accepted: 11 December 2019/Published online: 7 January 2020

(C) Springer-Verlag GmbH Germany, part of Springer Nature 2020

\begin{abstract}
Clonorchis sinensis (C. sinensis), an important fishborne zoonotic parasite threatening public health, is of major socioeconomic importance in epidemic areas. Effective strategies are still urgently expected to prevent against $C$. sinensis infection. In the present study, paramyosin of $C$. sinensis (CsPmy) was stably and abundantly expressed on the surface of Bacillus subtilis spores. The recombinant spores (B.s-CotC-CsPmy) were incorporated in the basal pellets diet in three different dosages $\left(1 \times 10^{5}, 1 \times 10^{8}, 1 \times 10^{11} \mathrm{CFU} / \mathrm{g}\right.$ pellets $)$ and orally administrated to grass carp (Ctenopharyngodon idella). The immune responses and intestinal microbiota in the treated grass carp were investigated. Results showed that specific anti-CsPmy IgM levels in sera, skin mucus, bile, and intestinal mucus, as well as mRNA levels of IgM and IgZ in the spleen and head kidney, were significantly increased in B.s-CotC-CsPmy-10 ${ }^{11}$ group. Besides, transcripts levels of IL- 8 and TNF- $\alpha$ in the spleen and head kidney were also significantly elevated than the control groups. Moreover, mRNA levels of tight junction proteins in the intestines of B.s-CotC-CsPmy-10 ${ }^{11}$ group increased. Potential pathogenetic bacteria with lower abundance and higher abundances of candidate probiotics and bacteria associated with digestion in $1 \times 10^{11} \mathrm{CFU} / \mathrm{g}$ B.s-CotC-CsPmy spores administrated fishes could be detected compared with control group. The amount of metacercaria in per gram fish flesh was statistically decreased in $1 \times 10^{11} \mathrm{CFU} / \mathrm{g}$ B.s-CotC-CsPmy spores orally immunized group. Our work demonstrated that B. subtilis spores presenting CsPmy on the surface could be a promising effective, safe, and needle-free candidate vaccine against C. sinensis infection for grass carp.
\end{abstract}

Keywords Clonorchis sinensis $\cdot$ Bacillus subtilis spore $\cdot$ Paramyosin $\cdot$ Oral vaccine $\cdot$ Intestinal microbiota $\cdot$ Grass carp

Hengchang Sun and Mei Shang contributed equally to this work.

Electronic supplementary material The online version of this article (https://doi.org/10.1007/s00253-019-10316-0) contains supplementary material, which is available to authorized users.

Yan Huang

huang66@mail.sysu.edu.cn

Xinbing Yu

yuxb@mail.sysu.edu.cn

1 Department of Laboratory Medicine, The Third Affiliated Hospital, Sun Yat-sen University, Guangzhou, China

2 Department of parasitology, Zhongshan School of medicine, Sun Yat-sen University, Guangzhou, China
3 Key Laboratory for Tropical Diseases Control, Sun Yat-sen University, Ministry of Education,, Guangzhou, Guangdong, China

4 Provincial Engineering Technology Research Center for Biological Vector Control, Guangzhou 510080, Guangdong, China

5 Department of Cell Biology and Genetics, School of Pre-clinical Medicine, Guangxi Medical University, Nanning 530021, China

6 Key Laboratory of Fishery Drug Development, Ministry of Agriculture, Pearl River, Fisheries Research Institute, Chinese Academy of Fishery Sciences, Guangzhou, Guangdong, China 


\section{Introduction}

Clonorchis sinensis (C. sinensis), an important fishborne zoonotic trematodes parasite, is prevalent in Asian countries and regions including China, South Korea, northern Vietnam, and Russia. Adult worms of $C$. sinensis live in the intrahepatic bile duct of definitive host. In addition to human beings, various other kinds of mammals can be definitive hosts of $C$. sinensis, such as cat, dog, pig, rabbits, etc. As reported, the average prevalences of $C$. sinensis infection in dogs and cats were $20.5 \%$ and $41.8 \%$ in the Pearl River Delta region which is the most important endemic area in Guangdong province (Lin et al., 2011). And nearly 35 million people are estimated to be infected with $C$. sinensis globally, of whom approximately 15 million are in China (Lai et al. 2016; Qian et al. 2016; Tang et al. 2016b) and bring a series of diseases like indigestion, biliary inflammation, bile duct obstruction, even liver cirrhosis, and hepatic carcinoma (Tang et al. 2016b). Accumulating evidence demonstrated that there is an aetiological relation between clonorchiasis and cholangiocarcinoma in human beings (Lun et al. 2005; Machicado and Marcos 2016; Zheng et al. 2017). However, we still lack effective strategy to completely prevent the spread of $C$. sinensis at present (Tang et al. 2016b). Human beings or other definitive hosts get infected by ingesting raw or undercooked fishes (the second intermediate hosts) containing live metacercaria (Lun et al. 2005). On the one hand, in epidemic areas wild animals served as the definitive hosts (reservoir hosts) for C. sinensis (Qian et al. 2016) which could be infectious source. For example, in Southern China, a large number of dogs and cats roam freely in rural settings, and the presence of these animals in proximity with people may represent a risk of parasitic zoonoses including C. sinensis (Fang et al. 2015; Nguyen et al. 2018). On the other hand, eating raw fish has been deeply rooted in culture of the area. In previous, most vaccine trials focused on the definitive host of $C$. sinensis instead of the intermediate hosts including freshwater fishes or snails (the first intermediate hosts). Protein-based or nucleic acid-based vaccine trials have been conducted on the rat model, but none of the vaccine candidates brought a protective effection (worm reduction rate) of more than 70\%(Qian et al. 2016; Tang et al. 2016b). Freshwater fishes (e.g., Ctenopharyngodon idellus, Carassius auratus, and Hypophthalmichthys nobilis) serve as the second intermediate host for $C$. sinensis. Hence, we speculate that cutting off the life cycle of $C$. sinensis by preventing the cercaria invasion or metacercariae formation in freshwater fish might be an efficacious tactic to control the prevalence of $C$. sinensis.

Vaccine has been the most effective method for combating infectious disease in aquaculture industry (Gudding and Van Muiswinkel 2013; Plant and Lapatra 2011). Compared with other immunization routes (injection and immersion route), oral vaccine is a preferable route as it is needle-free, no size limitation, lower cost, and more convenient for farmer operation (Plant and Lapatra 2011). However, oral immunization suffers from antigen degradation in the gastrointestinal tract of fish, which will affect the protective effect (Quentel and Vigneulle 1997). A considerable amount of investigations have proved that spores of Bacillus subtilis (B. subtilis) were a potent antigen delivery platform for oral vaccine (Ricca et al. 2014; Rosales-Mendoza and Angulo 2015; Tavares Batista et al. 2014). Because $B$. subtilis spores can survive extreme environment in the gastrointestinal tract, thus protect the antigens from digestion and degradation (Duc le et al. 2003). Besides, $B$. subtilis were widely employed as probiotic additives as it enhances the growth performance, digestive enzyme activities, immune responses, and disease resistance of fishes or shrimps (Liu et al. 2017; Sanchez-Ortiz et al. 2016; Truong Thy et al. 2017; Wang et al. 2010). B. subtilis spores were widely investigated as a delivery vehicle for the oral vaccine in aquaculture industry (Fu et al. 2010; Valdez et al. 2014).

In our previous work, an oral delivery system based on B. subtilis spore has been successfully established and confirmed to be valid and feasible (Jiang et al. 2017; Tang et al. 2017; Zhou et al. 2008). Enolase and cysteine protease of C. sinensis (CsENO and $\mathrm{CsCP}$ ) were expressed on the surface of $B$. subtilis spore, and the recombinant spores elicited both humoral and mucosal immune response in grass carp by oral immunization (Jiang et al. 2017; Tang et al. 2017). But the protect effect against C.sinensis and the safety of spores need further study.

Paramyosin (Pmy), an invertebrate muscle-associated multifunctional protein, has emerged as a promising vaccine candidate for various kinds of parasites (e.g., Schistosoma mansoni, Schistosoma japonicum, Taenia solium, Fasciola gigantica, etc.) (Abou-Elhakam et al. 2013; Jiz et al. 2015; Vazquez-Talavera et al. 2001). Paramyosin of $C$. sinensis (CsPmy, Accession number: JQ041818.1) was found to be highly expressed at the stage of adult worm, metacercariae, and cercaria. Both prokaryotic expressed protein and DNA vaccine of CsPmy brought encouraging protect effect in rat models. Furthermore, CsPmy was confirmed to be an important component of cyst wall of metacercariae, which suggested us that CsPmy may play a vital role in metacercariae formation in freshwater fishes (Wang et al. 2012).

In the present study, we aimed to explore whether oral administration with $B$. subtilis spores expressing CsPmy on the surface would be an effective and safe measure to protect grass carp from $C$. sinensis infection. CsPmy were fusion expressed on the surface of $B$. subtilis spores with CotC, a coat proteins of $B$. subtilis spores, and the immune response and protect effect in grass carp elicited by oral administration with the recombinant spores were evaluated. Besides, its influence on intestines and the intestinal microbiota of immunized grass carp were also investigated by using qRT-PCR and MiSeq high-throughput sequencing, respectively. 


\section{Method and materials}

\section{Fishes and recombinant $B$. subtilis spores}

Healthy grass carp weighing 20-25 g were acquired from Seedling Production Base of Pearl River Fisheries Institute (Guangzhou, China) and kept in the laboratory for acclimation for 2 weeks. Subsequently, fishes were divided into several tanks with the same volume of water (35 fishes per tank) and fed daily. Before experiments, fishes were randomly sampled for metacercaria detection according to the methods described previously (Liang et al. 2009) to confirm negative infection.

B. subtilis spore fusion expressing CotC-CsPmy (B.sCotC-CsPmy) and B. subtilis spore expressing CotC (B.s$\operatorname{Cot} C$ ) as the control were obtained by our previous study and preserved in our lab (Sun et al. 2018).

\section{Extraction of coat protein of spores}

B. subtilis WB600 strains with B.s-CotC-CsPmy or B.s-CotC was cultured in Difco Sporulation Medium (DSM, BD, Franklin Lakes, USA) for $24 \mathrm{~h}$ as described. Spores were harvested and washed with $1 \mathrm{M} \mathrm{NaCl}, 1 \mathrm{M} \mathrm{KCl}$ and distilled water in turn (Nicholson WL 1990). Finally, spores were resuspended in distilled water and treated in $68^{\circ} \mathrm{C}$ for $1 \mathrm{~h}$ to kill residue vegetative cell. They were counted and stored in $-80{ }^{\circ} \mathrm{C}$ prior to use.

To extract the coat proteins of spores, spores were resuspended with sodium dodecyl sulfate (SDS)-dithiothreitol (DTT) extraction buffer $(0.5 \%$ SDS, $0.1 \mathrm{M}$ DTT, $0.1 \mathrm{M}$ $\mathrm{NaCl}$ ) and incubated at $37{ }^{\circ} \mathrm{C}$ for $2 \mathrm{~h}$ (Tang et al. 2016a). Followed by six times wash with $1 \mathrm{M}$ Tris-HCl buffer (pH 8.0), the spores were suspended in $5 \mathrm{ml}$ broken buffer (50 mM Tris-HCl, $0.5 \mathrm{mM}$ EDTA, $1 \mathrm{mM}$ PMSF) and ultrasonicated for $5 \mathrm{~min}$. After centrifugation, the coat proteins were collected from the sediment, and the supernatant was preserved for further analysis as well (Tang et al. 2016a; Zhou et al. 2008).

\section{Protein identification by mass spectrometry}

B.s-CotC-CsPmy spores were analyzed by $12 \%$ SDS-PAGE. The corresponding expression band of CotC-CsPmy in the polyacrylamide gel was digested with trypsin as described before (Katayama et al. 2001). The peptides were analyzed through liquid chromatography coupled with tandem mass spectrometry (LC-MS/MS) with an LTQ Orbitrap Velos Pro mass spectrometer (Thermo Finnigan, USA). Mascot V2.3 search engine (Matrix Science, London, UK) was applied for protein identification using the following search parameters: Clonorchis sinensis database; two missed cleavage site; fixed modifications of Carbamidomethyl (C); partial modifications of Acetyl (Protein N-term), Deamidated (NQ),
Deoxidation (W), Oxidation (M); and $\pm 30 \mathrm{ppm}$ for precursor ion tolerance and $\pm 0.15 \mathrm{Da}$ for fragment ion tolerance.

\section{Diet preparation and oral administration}

The basal diet was a commercial pellet (Taifeng, Foshan, China, with the chemical composition of crude protein $\geq$ $30.0 \%$, crude fat $\geq 3.0 \%$, ash $\leq 13.0 \%$, crude cellulose $\leq$ $12.0 \%$, lysine $\geq 1.3 \%$, and total phosphorus $\geq 0.7 \%$ ). Five experimental diets were prepared in accordance with the methods described before (Jiang et al. 2017; Tang et al. 2017). Naïve group was treated with basal feed without spores. The control group (B.s-CotC- $10^{8}$ group) was administrated with basal feed plus B.s-CotC spores $\left(1 \times 10^{8} \mathrm{CFU} / \mathrm{g}\right)$. Experimental groups were managed with $1 \times 10^{5} \mathrm{CFU} / \mathrm{g}, 1 \times$ $10^{8} \mathrm{CFU} / \mathrm{g}$, or $1 \times 10^{11} \mathrm{CFU} / \mathrm{g}$ of B.s-CotC-CsPmy spores. To avoid dispersion of the spores in water, spores and basal feed were coated with an equal volume of cod liver oil (Tang et al. 2017). The diets were dried and stored at $-20^{\circ} \mathrm{C}$ until use. For oral immunization, fishes in each group were hand-fed with $2 \%$ of their initial body weight twice per day (at 09:00 am and 17:00 pm) for 6 weeks. Thereafter, fishes were fed with basal diet till the end of the experiment.

\section{Samples collection}

Five fishes were randomly sampled from each group at week 2, 4, and 6 after the beginning of the immunization. Grass carp was euthanized with overdose of eugenol mixture, and then skin mucus, blood, gallbladder, intestinal mucus, head kidney, and spleen were collected as described method (Guo et al. 2016). Briefly, skin mucus was gently scraped with a glass slide, then diluted with $0.5 \mathrm{ml}$ sterile PBS, centrifuge at $4{ }^{\circ} \mathrm{C}$, $4500 \mathrm{rpm}$ for $20 \mathrm{~min}$, and stored in $-80^{\circ} \mathrm{C}$ (Tang et al. 2017). Blood was collected from the caudal vein using a $1 \mathrm{ml}$ injector, clotted in the room temperature for $2 \mathrm{~h}$, and then sera were separated by centrifugation $\left(4^{\circ} \mathrm{C}, 4000 \mathrm{rpm}\right.$ for $\left.15 \mathrm{~min}\right)$ and stored in $-20^{\circ} \mathrm{C}$ until use (Jiang et al. 2017). The intestine was aseptically isolated, lavaged with $0.5 \mathrm{ml}$ sterile PBS for several times, and centrifugated $\left(4^{\circ} \mathrm{C}, 4500 \mathrm{rpm}\right.$ for $\left.20 \mathrm{~min}\right)$. The supernatant of the lavage fluid was stored at $-20^{\circ} \mathrm{C}$. The spleen and head kidney of each fish was dissected and preserved in sample protector (Takara Bio, Otsu, Japan) in $-80{ }^{\circ} \mathrm{C}$. About 8 weeks after the beginning of administration, another three fishes in each group were sampled and euthanized, and the whole intestines of the three fishes were aseptically excised for gut microbiota analysis.

\section{Analysis of CsPmy-specific IgM}

Indirect enzyme-linked immunosorbent assay (ELISA) was employed to analyze the specific antibody levels against CsPmy in samples including skin mucus, sera, bile, and 
intestinal mucus. In brief, the 96-well microtiter plates were coated with $100 \mathrm{ml}$ per well of $5 \mu \mathrm{g} / \mathrm{ml} \mathrm{rCs} P$ my carbonatebicarbonate buffer $\left(0.05 \mathrm{M}\right.$, pH 9.6) in $4{ }^{\circ} \mathrm{C}$ overnight. After washing with PBST three times, the plates were blocked with blocking buffer containing $5 \%$ skimmed milk for $2 \mathrm{~h}$ at $37^{\circ} \mathrm{C}$. Meanwhile, sera, bile, skin mucus, and intestinal mucus was diluted with 1\% BSA in PBST at a dilution of 1:100, 1:100, $1: 20,1: 20$, respectively. Then $0.1 \mathrm{ml}$ of diluted samples were added to each well as primary antibody and incubated for $2 \mathrm{~h}$ at $37^{\circ} \mathrm{C}$. After three times washing, $0.1 \mathrm{ml}$ of HRP-conjugated rabbit anti-grass carp IgM (diluted at 1:7000) was added and incubated at $37^{\circ} \mathrm{C}$ for $1 \mathrm{~h}$. The plates were washed for 3 times again, $0.1 \mathrm{ml}$ of tetramethylbenzidine (TMB, BD, USA) was added and reacted at RT for $10 \mathrm{~min}$. Finally, the reaction was terminated by adding $50 \mu \mathrm{l}$ of $2 \mathrm{M} \mathrm{H}_{2} \mathrm{SO}_{4}$, and the optical density value at $450 \mathrm{~nm}$ was detected by a microplate reader.

\section{mRNA levels of immune-related molecules and tight junction proteins by quantitative real-time polymerase chain reaction (qRT-PCR)}

About 6 weeks after the beginning of oral administration, total RNA was extracted from the head kidney, spleen, foregut, midgut, or hindgut tissues of grass carp with TRIzol reagent (TransGen Biotech, Beijing, China) and was reverse transcribed into the first strand of cDNA by using an All-in-One First-Strand cDNA Synthesis SuperMix Kit (TransGen Biotech, Beijing, China). mRNA levels of immunoglobulin M (IgM), immunoglobulin Z (IgZ), tumor necrosis factor $\alpha$ (TNF- $\alpha$ ), and interleukin 8(IL-8) in the head kidney and spleen were analyzed by qRT-PCR. Additionally, transcription levels of gene encoding tight junction proteins including ZO1 , occludin, claudin $b$, and claudin $c$ were also detected. $\beta$ actin was used as an internal reference gene (Feng et al. 2015). The specific primers were designed according to the published grass carp sequences and were listed in Table S1. The qRTPCR procedure was carried out by the process described (Jiang et al. 2017). Data were analyzed by the $2^{-\Delta \Delta C t}$ method with CFX Manager Software.

\section{Gut microbiome analysis}

The whole intestines of the three fishes were aseptically excised and opened and rinsed with sterilized PBS to remove the contents. Intestines from three fishes in the same group were collected into one sterile centrifuge tube. The intestinal samples were homogenized with sterilized PBS. The genomic DNA was extracted using OMEGA D3350 Bacterial DNA Kit (Omega, USA) according to manufacturer's protocols. The V3-V4 regions of 16S ribosomal DNA of bacteria were amplified, purified, and pooled in equimolar and paired-end sequenced $(2 \times 250 \mathrm{bp})$ on an Illumina MiSeq platform $(\mathrm{OE}$ Biotech, Shanghai, China).
Data was demultiplexed, quality filtered, and analyzed with QIIME(v1.8.0) and UCHIME (v4.2)(Caporaso et al. 2010; Edgar et al. 2011). Operational taxonomic units (OTUs) were generated using VSEARCH (v2.4.2) software with $97 \%$ similarity cutoff. All representative reads were annotated and blasted against Silva database (v123) using RDP classifier (v2.2) with the confidence threshold of $70 \%$ (Hao et al. 2017a). Bias-corrected Chao1 richness estimator (Chao 1) was applied to evaluate the community richness. Shannon-Wiener Index (Shannon) and Simpson's diversity index (Simpson) was used for diversity evaluation for each sample. The structures of the microbial community in different samples were compared based on the column diagram, heat map analysis, and principal-component analysis (PCA) (Hao et al. 2017a). The bacterial abundance was analyzed among the groups. All the Illumina sequencing data has been deposited in the NCBI Sequence Read Archive database (http://www.ncbi.nlm.nih.gov/sra/), and the accession numbers were SRR10244385/ SRR10244384/ SRR10244383/SRR10244382/SRR10244381.

\section{Challenge infection}

Parafossarulus striatulus, the first intermediate host of C. sinensis, were captured from Yangshan county, Guangdong province, China, and were elaborately cultivated in our laboratory. After 2 weeks acclimation, the Parafossarulus striatulus were fed with $C$. sinensis eggs. Ninety days later, snails were checked every day for cercariae release (Liang et al. 2009). Water with living cercariae was collected every day and was equally divided into each tank to infect fishes in the naïve group $(n=5)$, B.s-CotC- $10^{8}$ group $(n=5)$, and B.s-CotCCsPmy-10 ${ }^{11}$ group $(n=5)$. Challenge infection lasted for 7 days. Four weeks post the challenge infection, all fishes were sacrificed. The flesh was weighted, cut into pieces, and separately digested with artificial gastric juice for C.sinensis metacercaria detection. The number of metacercaria in per gram flesh of fish was calculated.

\section{Statistical analysis}

Data in experiments were expressed as the mean $\pm \mathrm{SD}$ values. Student's $t$ test was applied to analyze statistical differences in mRNA levels and number of metacercaria in per gram flesh among different groups using GraphPad Prism 5 software (version 5.0 for windows). One-way analysis of variance (ANOVA) with Tukey tests were used to analyze statistical differences of antibody levels with GraphPad Prism 5 software (version 5.0 for windows). The difference was considered as statistically significant if the $P$ value $<0.05$. 


\section{Results}

\section{Acquirement of recombinant spore of B.s-CotC-CsPmy}

SDS-PAGE and western blotting by using anti-CsPmy antibody showed that CotC-CsPmy expressed in coat proteins extracted from the recombinant $B$. subtilis spores (Fig. 1A, B). Flow cytometry showed that $58.4 \%$ of B.s-CotC-CsPmy spores exhibited a strong fluorescence intensity ranging from $10^{4}$ to $10^{6}$ by anti-CsPmy serum as a primary antibody (Fig. 1C). LC-MS/MS confirmed the protein band with $100 \mathrm{kDa}$ as CsPmy (Fig. 1D and Table S2).

\section{Specific IgM levels in sera, skin mucus, intestinal mucus, and bile}

Compared with Naïve groups and B.s-CotC groups, specific anti-CsPmy IgM levels in sera, skin mucus, intestinal mucus, and bile samples from fishes of B.s-CotC-CsPmy groups raised since week 2 and went on rising till week 6 (Fig. 2). In the skin mucus, IgM level significantly elevated from week 4 (Fig. 2B), which raised later than those in sera, intestinal mucus, and bile samples (Fig. 2A, C, D). Compare with the $10^{5}$ dosage group, $10^{8}$ and $10^{11}$ dosage groups elicited higher IgM level. The highest one was $10^{11}$ dosage group (Fig. 2).

\section{mRNA levels of IgM and $\lg Z$ in the head kidney and spleen}

Compared with naïve groups, the mRNA levels of IgM and IgZ in middle dosage $\left(1 \times 10^{8} \mathrm{CFU} / \mathrm{g}\right.$ B.s-CotC-CsPmy spores $)$ and high dosage $\left(1 \times 10^{11} \mathrm{CFU} / \mathrm{g}\right.$ B.s-CotC - CsPmy spores) were significantly increased both in the head kidney and spleen. The mRNA levels of $\operatorname{IgM}$ and $\operatorname{IgZ}$ in $1 \times$ $10^{11} \mathrm{CFU} / \mathrm{g}$ groups were the highest. There was no significant difference in mRNA levels of IgM and IgZ in the head kidney and spleen between naïve group and B.s-CotC group. Compared with naïve group, there was no statistical increase of mRNA levels of IgM and IgZ in $1 \times 10^{5} \mathrm{CFU} / \mathrm{g}$ group except IgZ mRNA level in the head kidney (Fig. 3).

\section{Proinflammatory cytokines in the head kidney and spleen}

In the head kidney, TNF- $\alpha$ mRNA level of $1 \times 10^{11} \mathrm{CFU} / \mathrm{g}$ B.s-CotC-CsPmy group were significantly higher than those in naïve group and B.s-CotC group (Fig. S1A), while no significant differences were detected between those in $1 \times 10^{5}$ and $1 \times 10^{8} \mathrm{CFU} / \mathrm{g}$ B.s-CotC-CsPmy groups. IL- $8 \mathrm{mRNA}$ level was significantly raised compared with both naïve group and B.s-CotC group. In spleen, mRNA levels of TNF- $\alpha$ and

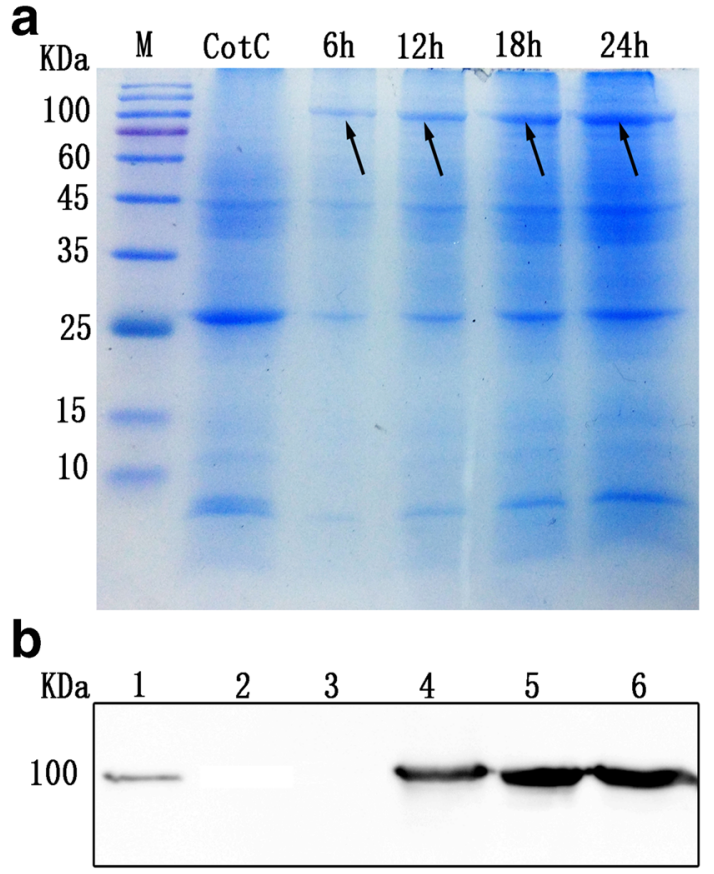

\section{C}
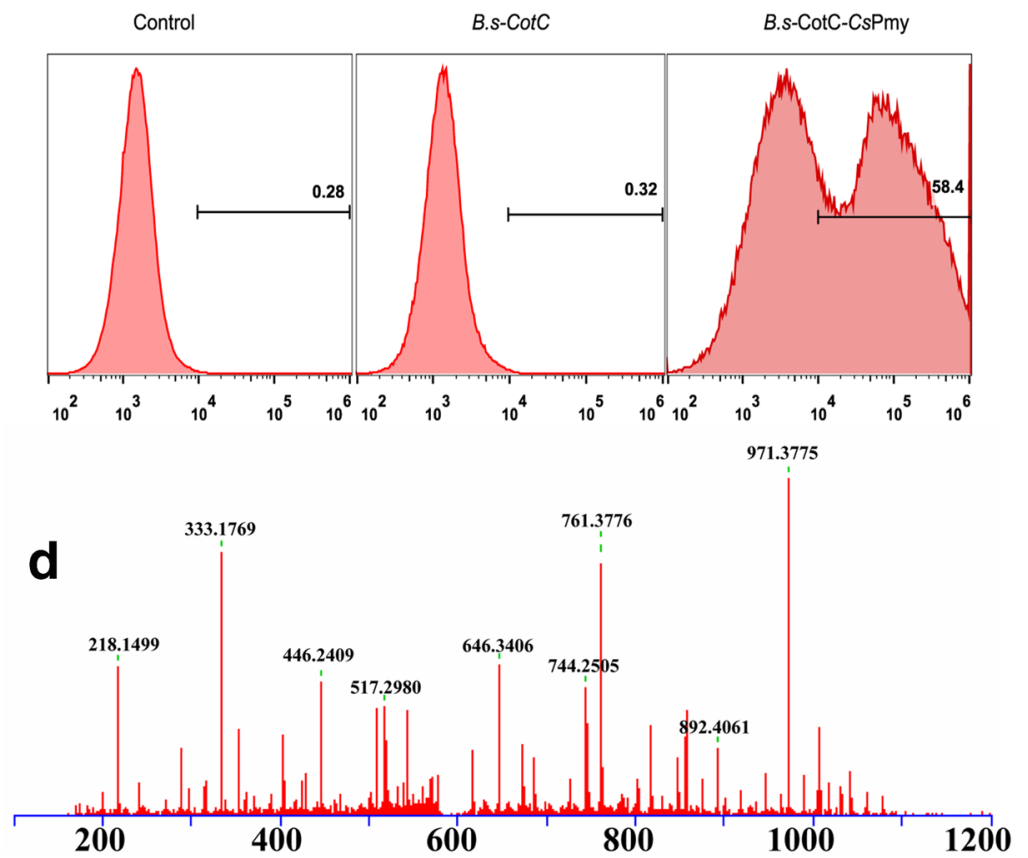

Fig. 1 Analysis of CsPmy expression on spore surface. A 12\% SDSPAGE analysis of CsPmy expression on B. subtilis spore at the different time point. The dark arrows indicated the band of CsPmy. M, protein marker; CotC, B.s-CotC spores; 6 h, 12 h, 18 h, 24 h, sporulation induction time of B.s-CotC-CsPmy. B Western blotting of CsPmy expression in coat proteins of B.s-CotC-CsPmy spores. Lane 1, recombinant protein of CsPmy; lane 2, coat protein of B.s-CotC spore;

lane 3, propagules of B.s-CotC-CsPmy; lane 4-6, coat protein of B.sCotC-CsPmy spore-induced for $6 \mathrm{~h}, 12 \mathrm{~h}$, and $24 \mathrm{~h}$, respectively. C Flow cytometry; Control, B. subtilis spores containing no plasmid; B.sCotC, B.subtilis spore containing PEB03-CotC plasmid; B.s-CotCCsPmy, B. subtilis spore harboring PEB03-CotC-CsPmy plasmid. D LC-MS/MS analysis of coat proteins of B.s-CotC-CsPmy. The paramyosin from $C$. sinensis was identified in coat proteins 

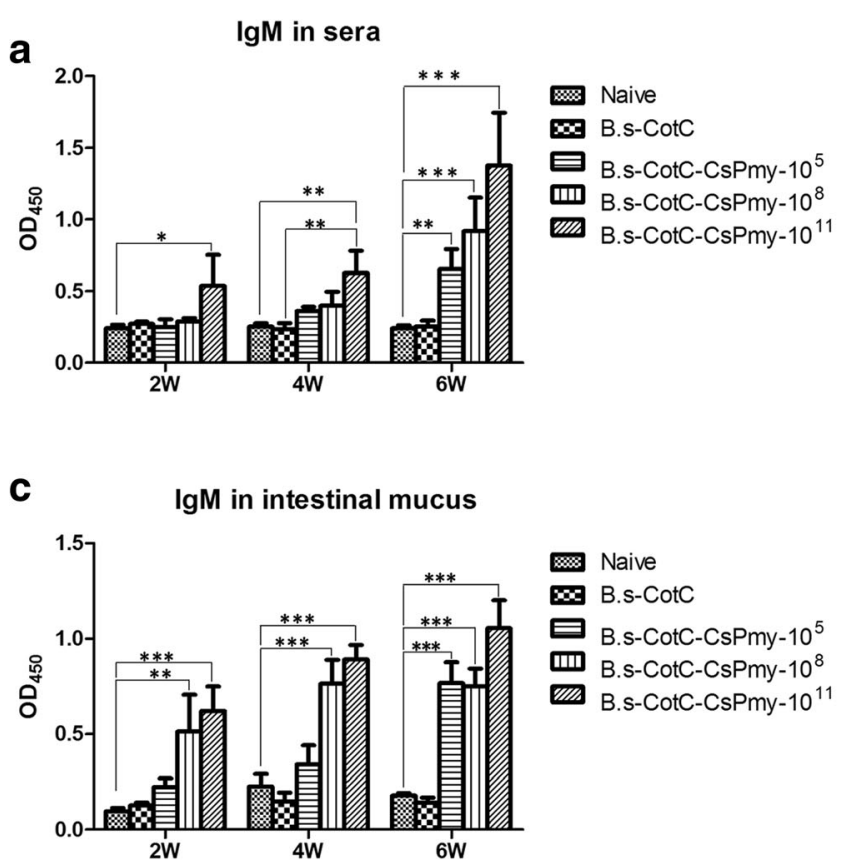

Fig. 2 Specific anti-CsPmy IgM levels in oral immunized grass carp Grass carp was orally administrated with different dosage of recombinant spores. Specific anti-CsPmy antibodies were determined by ELISA in week 2, 4, and 6 after the beginning of the oral immunization. (A) sera, (B) skin mucus, (C) intestinal mucus, (D) bile. Naïve, basal diet group;

IL-8 significantly increased in $1 \times 10^{8}$ and $1 \times 10^{11} \mathrm{CFU} / \mathrm{g}$ B.s-CotC-CsPmy groups compared with those in naïve group (Fig. S1B). No differences were detected between B.s-CotC and naïve group (Fig. S1).

\section{Transcriptional levels of genes encoding tight junction proteins}

To investigate the influences of oral administration of spores on the integrality of intestines mucosa, transcriptional levels of genes encoding tight junction proteins (ZO-1, occludin, claudin $b$, claudin c) in foregut, midgut, and hindgut of grass carp were analyzed. In the foregut, transcriptional levels of ZO-1, occludin, claudin b, and claudin c were the highest in fishes fed with $1 \times 10^{11} \mathrm{CFU} / \mathrm{g}$ B.s-CotC-CsPmy spores, which were significantly increased compared with those in fishes from naïve or B.s-CotC groups (Fig. S2A). The ZO-1 mRNA level in the midgut and hindgut were not dominantly affected by spores administration (Fig. S2B-a, C-a). Transcriptional levels of occludin, claudin b, claudin $\mathrm{c}$ in midgut, and hindgut of grass carp from $1 \times 10^{11}$ B.s-CotC-CsPmy spores group were obviously elevated compared with those of other groups (Fig. S2B, C).

\section{Intestinal microbiome analysis}

In total, 963 OTUs were generated from the samples through Illumina MiSeq sequencing, and these OTUs belong to 11

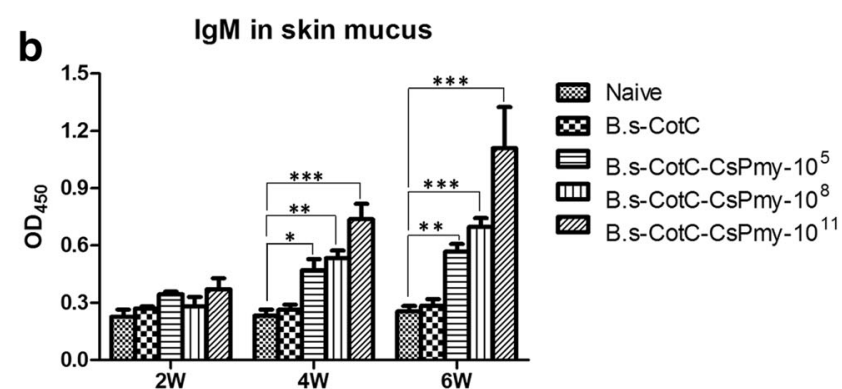

d

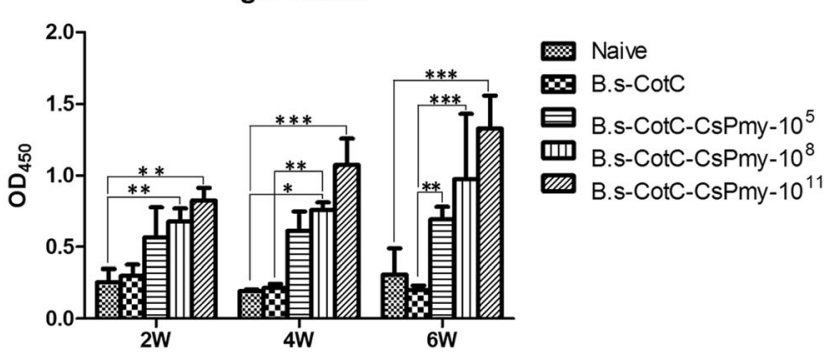

B.s-CotC- $10^{8}$ : basal diet plus $1 \times 10^{8} \mathrm{CFU} / \mathrm{g}$ B.s-CotC spores. B.s-CotCCsPmy- $10^{5}, 10^{8}, 10^{11}$, basal diet plus $10^{5}, 10^{8}, 10^{11} \mathrm{CFU} / \mathrm{g}$ B.s-CotCCsPmy spores, respectively. Data were represented as mean $\pm \mathrm{SD}$. Statistical significance was analyzed by the Dunnett's test. $* P<0.05$, $* * P<0.01, * * * P<0.001$

different phyla. Good's nonparametric coverage estimator (good's coverage) of each sample tend to approach 1 (Fig. 4Aa). Chao 1 index was used to estimate microbial community richness of the intestinal microbiota. The Chao 1 value in $1 \times$ $10^{11} \mathrm{CFU} / \mathrm{g}$ B.s-CotC-CsPmy spores (BH) group was the highest compared with those of other groups (Fig. 4A-b). Shannon index and Simpson index were calculated to evaluate microbial community diversity. Shannon and Simpson index value of BH group was the highest among the groups. Diversity index of B.s-CotC spores fed group (BC), $1 \times 10^{5} / 10^{8} / 10^{11} \mathrm{CFU} / \mathrm{g}$ B.s-CotCCsPmy spores treated groups (BL, BM, BH) were higher than that of control group (NC) (Fig. 4A-c, d). The shared and unique OUTs among the samples were investigated and showed in the Venn diagram. A total of 84 OTUs were shared by all the 5 groups, and 45 unique OUTs were detected in $\mathrm{BH}$ group, which was the largest number among groups (Fig. 4B).

Principal components analysis (PCA) with weighted UniFrac method was applied to analyze the relationships between bacterial communities from different groups. The score plot of PCA revealed that microbial communities from BC, $\mathrm{BL}, \mathrm{BM}$, and $\mathrm{NC}$ groups were gathered at left-hand side of the plot along the second principal component axis (PC2), which accounts for $72.1 \%$ of the total variations. However, BH group was on right side of the graph along PC2. BL group was separated from the other groups along PC1, which represented $14.08 \%$ of the total variations. In general, the two axes (PC1 and PC2) explained $86.18 \%$ (Fig. 4C). In addition, the 
Fig. 3 The relative mRNA levels of IgM and IgZ in the head kidney and spleen. The mRNA levels of IgM and IgZ were analyzed by qRT-PCR at 6 weeks after the beginning of the immunization. (A) IgM mRNA level in the head kidney; (B) IgZ mRNA level in the head kidney; (C) IgM mRNA level in the spleen; (D) IgZ mRNA level in the spleen. Naïve, basal diet group; B.s-CotC- $10^{8}$ : basal diet plus $1 \times 10^{8} \mathrm{CFU} / \mathrm{g}$ B.s-CotC spores. B.s-CotC-CsPmy-10 $0^{5}$, $10^{8}, 10^{11}$, basal diet plus $10^{5}, 10^{8}$, $10^{11} \mathrm{CFU} / \mathrm{g}$ B.s-CotC-CsPmy spores, respectively. $* P<0.05$, $* * P<0.01$ (compared with naïve group); $\# P<0.05$, \#\# $P<0.01$ (compared with B.s-CotC-10 group) a

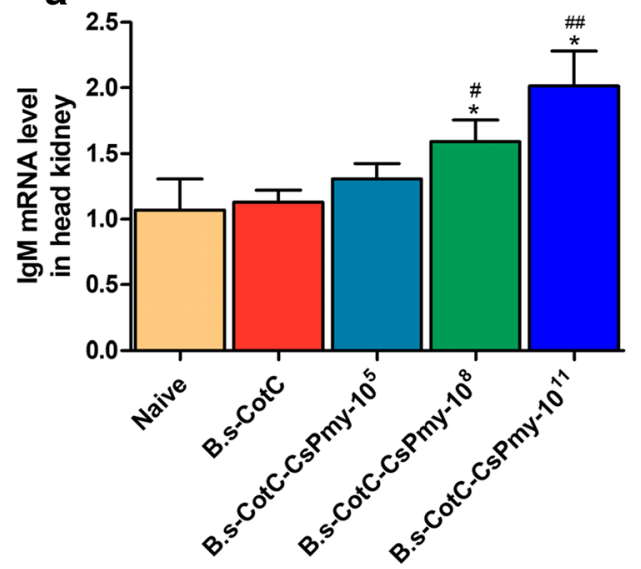

b

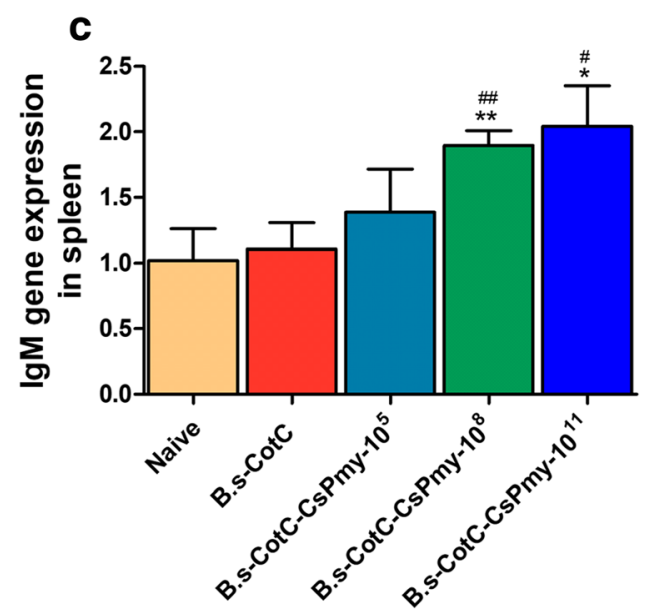

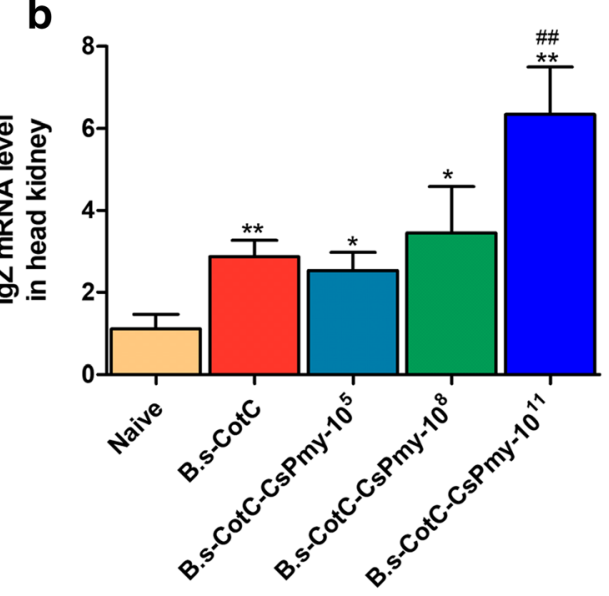

d

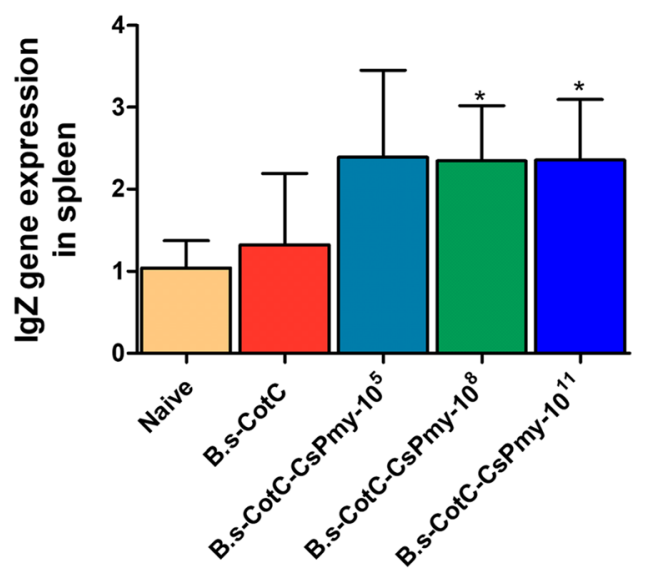

differences among the groups were also observed in the heatmap, which showed the bacteria ranking top 30 in the abundance. (Fig. 4D).

Proteobacteria, Fusobacteria, Firmicutes, and Spirochaetae were main bacteria phyla in all grass carp, accounting for more than $99 \%$ of bacteria. Firmicutes were the most predominant phylum in BH group $(25.38 \%)$, followed by Fusobacteria (8.2\%). In NC, BC, and BM groups, Proteobacteria had the highest abundance accounted for $23.74 \%, 58.55 \%$, and $51.15 \%$, respectively (Table 1 ).

The abundance of potential pathogenetic bacteria such as Pseudomonas and Flavobacterium were detected in samples. The amount of sequences related to Pseudomonas in $\mathrm{BH}$ group decreased compared with that in NC group. Flavobacterium with lower abundance was found in NC and $\mathrm{BL}$ groups but not in BH, BC, and BM groups. (Table 2). Candidate probiotics including Lactobacillus, Streptococcus, and Micrococcus were also detected and analyzed. Higherabundance Lactobacillus and Streptococcus genus were found in BH group compared with NC group. Micrococcus could not be detected in all samples (Table 2).

In addition, sequences related to bacteria associated with digestion were also investigated. The abundance of Rikenellaceae, Ruminococcaceae, and Lachnospiraceae (at family level) varied in different groups, but they were dramatically increased in BH group compared with other groups (Table 3). The abundances of Odoribacter, Desulfovibrio, and Alistipes were higher in $\mathrm{BH}$ group than those in $\mathrm{NC}$, $\mathrm{BL}$, and BM groups.

\section{Protect effect of the recombinant spores}

After the challenge infection with living cercaria (Fig. 5A), C. sinensis metacercaria (Fig. 5B) was found in all treated fishes. The average amount of metacercaria per gram fish flesh in the naive group, B.s-CotC- $10^{8}$ group, and B.s-CotC-CsPmy$10^{11}$ group was $13.2,12.4$ and 7.2, respectively (Fig. $5 \mathrm{C}$ ).

\section{Discussion}

In the current study, we orally administrated grass carp with $1 \times 10^{5}, 1 \times 10^{8}$ or $1 \times 10^{11} \mathrm{CFU} / \mathrm{g}$ B. subtilis spores surface displaying CsPmy. The results showed that specific antiCsPmy IgM levels in sera, skin mucus, intestinal mucus, and bile samples from fishes in B.s-CotC-CsPmy spores orally treated groups dominantly increased. In $1 \times 10^{11} \mathrm{CFU} / \mathrm{g}$ B.sCotC-CsPmy spores administrated fishes, mRNA levels of 


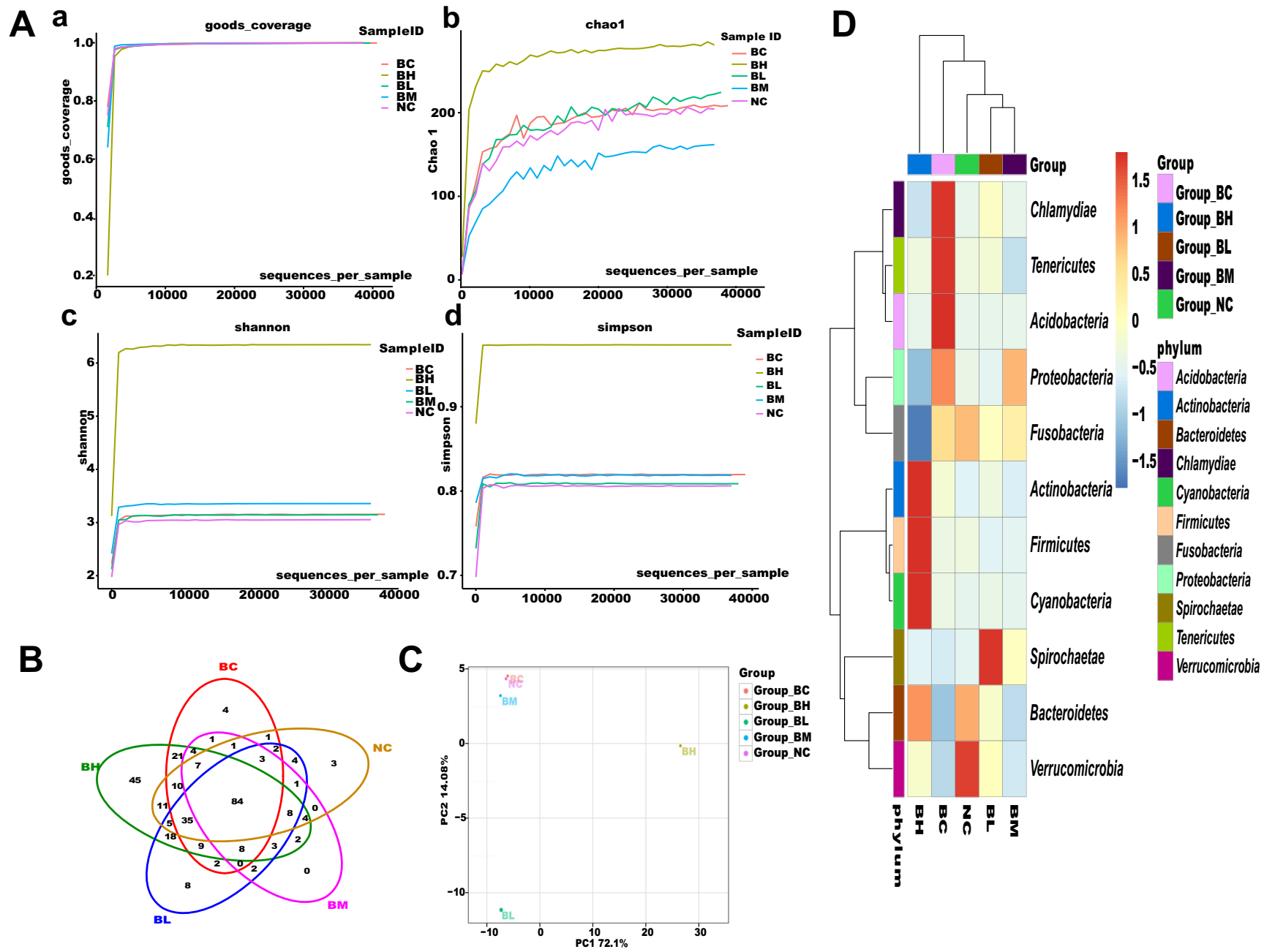

Fig. 4 Intestinal microbiota analysis. Intestines from three fishes in the same group were homogenized for intestinal microbiota analysis. A Alpha diversity analysis. a Good's nonparametric coverage estimator. b Chao1 index. c Shannon index. d Simpson index. B Venn graph showing the unique and shared OTUs among groups. C Scatterplot of PCA-score depicting variance of fingerprints derived from the different bacterial community. The principal components $\mathrm{PC} 1$ and $\mathrm{PC} 2$ explained $72.1 \%$ and $14.08 \%$ of the variance, respectively. D Heatmap of bacterial

Table 1 Relative abundance of bacteria at phyla level in each group

\begin{tabular}{llllll}
\hline Groups & $\mathrm{BC}(\%)$ & $\mathrm{BH}(\%)$ & $\mathrm{BL}(\%)$ & $\mathrm{BM}(\%)$ & $\mathrm{NC}(\%)$ \\
\hline Spirochaetae & 0.32 & 1.40 & 26.37 & 7.11 & 1.76 \\
Firmicutes & 2.78 & 25.38 & 1.20 & 1.57 & 3.18 \\
Fusobacteria & 17.28 & 8.20 & 14.86 & 16.00 & 18.23 \\
Proteobacteria & 58.55 & 7.40 & 21.54 & 51.15 & 23.74 \\
Other & 0.75 & 1.91 & 0.30 & 0.11 & 0.19 \\
\hline
\end{tabular}

Numbers represent the relative abundance of the predominant bacterial phyla. $\mathrm{NC}$, fishes were fed with basal diet; $\mathrm{BC}$, fishes were fed with pellets covered with B.s-CotC spores $\left(1 \times 10^{8} \mathrm{CFU} \mathrm{g}^{-1}\right.$ pellets); $\mathrm{BL}, \mathrm{BM}, \mathrm{BH}$, fishes were fed with pellets covered with dosages of $1 \times 10^{5}, 1 \times 10^{8}, 1 \times 10^{11} \mathrm{CFU} \mathrm{g}^{-1}$ pellets of B.s-CotCCsPmy spores, respectively distribution in groups. The relative abundance of the bacterial genus is depicted by color intensity with legend indicated at the right side of the figure. Clusters based on the distance of five groups along $\mathrm{X}$-axis and bacterial genus along Y-axis were showed in upper and left of the figure, respectively. Naïve, basal diet group; B.s-CotC-10 ${ }^{8}$ : basal diet plus $1 \times 10^{8} \mathrm{CFU} / \mathrm{g}$ B.s-CotC spores. B.s-CotC-CsPmy$10^{5}, 10^{8}, 10^{11}$, basal diet plus $10^{5}, 10^{8}, 10^{11} \mathrm{CFU} / \mathrm{g}$ B.s-CotCCsPmy spores, respectively

IgM, IgZ, TNF- $\alpha$, and IL- 8 significantly elevated in the head kidney and spleen, and transciptional levels of tight-junction proteins in foregut, midgut, and hindgut of grass carp obviously increased too. Gut microbiome indicated that potential pathogenetic bacteria with lower abundance and higher abundances of candidate probiotics and bacteria associated with digestion in $1 \times 10^{11} \mathrm{CFU} / \mathrm{g}$ B.s-CotC-CsPmy spores administrated fishes were detected. The amount of metacercaria in per gram fish flesh were statistically decreased in $1 \times 10^{11} \mathrm{CFU} / \mathrm{g}$ B.s-CotC-CsPmy spores orally immunized group.

In the past years, the prevention and management of the C. sinensis mainly relied on an integrated control strategy including chemotherapy of infected patients, management or 
Table 2 Abundance of potential pathogenetic bacteria or candidate probiotics present in samples

\begin{tabular}{llllll}
\hline Groups & $\mathrm{NC}$ & $\mathrm{BC}$ & $\mathrm{BL}$ & $\mathrm{BM}$ & $\mathrm{BH}$ \\
\hline Flavobacterium $^{*}$ & 6 & 0 & 1 & 0 & 0 \\
Pseudomonas $^{*}$ & 128 & 131 & 106 & 103 & 51 \\
Streptococcus $^{\#}$ & 6 & 13 & 9 & 8 & 44 \\
Lactobacillus $^{\#}$ & 6 & 5 & 2 & 0 & 14 \\
Micrococcus $^{\#}$ & 0 & 0 & 0 & 0 & 0 \\
\hline
\end{tabular}

The numbers represent the total abundance of bacteria genus presented in the community. $\mathrm{NC}$, fishes were fed with basal diet; $\mathrm{BC}$, fishes were fed with pellets covered with B.s-CotC spores $\left(1 \times 10^{8} \mathrm{CFU} \mathrm{g}^{-1}\right.$ pellets $)$; $\mathrm{BL}, \mathrm{BM}, \mathrm{BH}$, fishes were fed with pellets covered with dosages of $1 \times 10^{5}, 1 \times 10^{8}, 1 \times 10^{11} \mathrm{CFU} \mathrm{g}^{-1}$ pellets B.s-CotC-CsPmy spores, respectively

* represent the Potential pathogenetic bacteria

\# the candidate probiotics

sterilization of feces, implementation of education campaigns, etc. (Huang et al. 2017; Lun et al. 2005; Qian et al. 2016). This strategy helped to reduce the infection rate of $C$. sinensis in human beings to a certain degree (Qian et al. 2016), but surveys showed that, in some epidemic areas, the prevalence of C.sinensis has been increasing over the years (Lun et al. 2005). Hence, vaccine or more effective drugs are urgently expected to control the spread of $C$. sinensis.

A lot of research works had explored vaccine against C.sinensis in recent years, but almost of them were focused on vaccine for the final host (Tang et al. 2016b). To our knowledge, eating raw or undercooked fish flesh harboring living metacercaria is the only route for human being or animals to get infected with $C$. sinensis. In view of this status, we speculated that cutting off the life cycle of $C$. sinensis by interfering the metacercariae formation in freshwater fish might be a potential strategy.

Table 3 Digestion-related bacteria presented in samples

\begin{tabular}{llllll}
\hline Groups & $\mathrm{NC}$ & $\mathrm{BC}$ & $\mathrm{BL}$ & $\mathrm{BM}$ & $\mathrm{BH}$ \\
\hline Rikenellaceae $^{\#}$ & 567 & 310 & 414 & 202 & 3349 \\
Ruminococcaceae $^{\#}$ & 47 & 95 & 50 & 24 & 2346 \\
Lachnospiraceae $^{\#}$ & 222 & 347 & 294 & 375 & 6141 \\
Odoribacter* $^{*}$ & 58 & 117 & 64 & 11 & 2546 \\
Desulfovibrio* $^{*}$ & 1 & 2 & 2 & 0 & 19 \\
Alistipes* $^{*}$ & 40 & 71 & 50 & 12 & 2071 \\
\hline
\end{tabular}

The numbers represent the total abundance of bacteria genus presented in the community. NC, fishes were fed with basal diet; $\mathrm{BC}$, fishes were fed with pellets covered with B.s-CotC spores $\left(1 \times 10^{8} \mathrm{CFU} \mathrm{g}{ }^{-1}\right.$ pellets $)$; $\mathrm{BL}, \mathrm{BM}, \mathrm{BH}$, fishes were fed with pellets covered with dosages of $1 \times$ $10^{5}, 1 \times 10^{8}, 1 \times 10^{11} \mathrm{CFU} \mathrm{g}^{-1}$ pellets B.s-CotC-CsPmy spores, respectively

\# at family level

*at genus level
In our previous work, oral vaccines based on $B$. subtilis spore expressing enolase or cysteine protease of $C$. sinensis has already been tested on grass carp and proved to be able to induce both system and local mucosal immune response of fish (Jiang et al. 2017; Tang et al. 2017). But immune protect effect elicited from vaccine candidates besides the two molecules still needs further evaluation and confirmation (Tang et al. 2017). CsPmy, as a multifunctional molecular and important component of cyst wall of $C$. sinensis metacercaria, has been well characterized as a vaccine candidate (Wang et al. 2012). In the current study, CsPmy was displayed on the surface of $B$. subtilis spores by using a coat protein $(\mathrm{CotC})$ as an anchor. SDS-PAGE, western blotting, flow cytometry, and LC-MS/MS verified the successful expression of CsPmy (Fig. 1).

Recombinant $B$. subtilis spores are firstly took in by the M cells in intestinal mucosa and transported into Peyer's patches. Antigens presented on the surface of spores interact with mucosa-associated lymphoid tissues (MALTs) and other systemic lymphoid tissues, resulting in a series of immune responses including secretion of immune globulins (Rosales-Mendoza and Angulo 2015; Tang et al. 2016a; Tavares Batista et al. 2014). In bony fishes, as there are a lot of lymphoid cells, macrophages, eosinophilic, neutrophilic granulocytes, and other secretory cells in skin, it is also a main tissue-producing mucosal immune response besides intestinal mucosa (Salinas 2015). Antigen-specific immune globulins (e.g., IgM and IgZ) were secreted from intestinal mucus and skin mucus when they were stimulated by heterogeneous antigens so that they serve as the first line of immunological barriers against pathogenic invasion (Zhu et al. 2013). Well-studied IgM is the main kind of immune globulins in grass carp. IgZ, analogous to mammalian IgA, also plays a specialized role in mucosal immune responses of fish (Xu et al. 2013).

In the present study, the specific IgM antibody levels in serum, bile, intestinal mucus, and skin mucus of grass carp orally administrated with different dosages of spores (B.sCotC-CsPmy) were significantly increased with dosedependent from the 2nd week after the beginning of the immunization till to 6 weeks (Fig. 2). Our results were coincident with the former reports about immune response in grass carp induced by oral immunization with spore expressing enolase or cysteine protease of $C$. sinensis (Jiang et al. 2017; Tang et al. 2017). Moreover, mRNA levels of IgM and IgZ were up-regulated in the head kidney and spleen of fishes from B.sCotC-CsPmy spores orally treated groups (Fig. 3). The results verified that CsPmy on the spore surface could be recognized by immune system in intestinal mucosa and obviously elicit strong systemic and local mucosal immune response in grass carp by oral administration, especially treated with high dosage (B.s-CotC-CsPmy-10 $0^{11}$ ). 
Fig. 5 Protect effect in orally administrated fishes. Fishes were sacrificed at 4 weeks after the challenge infection. Fish flesh in each group was weighted and digested with artificial gastric juice $(\mathrm{PH}=2.0)$ for metacercaria detection. (A) C. sinensis cercaria used for challenge infection. (B) Metacercariae found in grass carp after challenge infection. (C) Amount of metacercaria per gram fish flesh. Naïve, fishes fed with basal diet. B.s-CotC- $10^{8}$, fishes fed with basal diet plus $1 \times$ $10^{8} \mathrm{CFU} / \mathrm{g}$ B.s-CotC spores; B.sCotC-CsPmy-10 $0^{11}$, fishes fed with basal diet plus $10^{11} \mathrm{CFU} / \mathrm{g}$ B.s-CotC-CsPmy spores.

$* * P<0.01$ (compared with Naïve group), $\# \# P<0.05$ (compared with B.s-CotC- $10^{8}$ group). 100 magnification for $\mathrm{A}$ and 200 magnification for $\mathrm{B}$ a

b

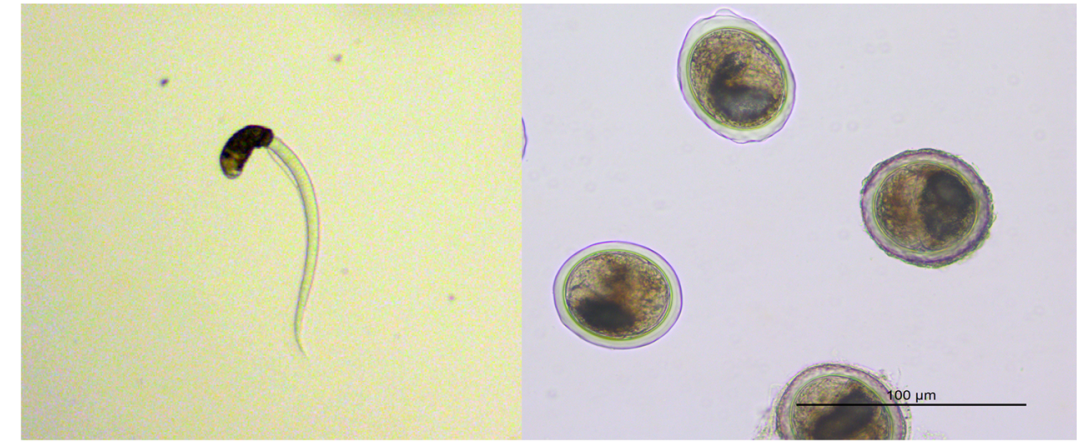

c

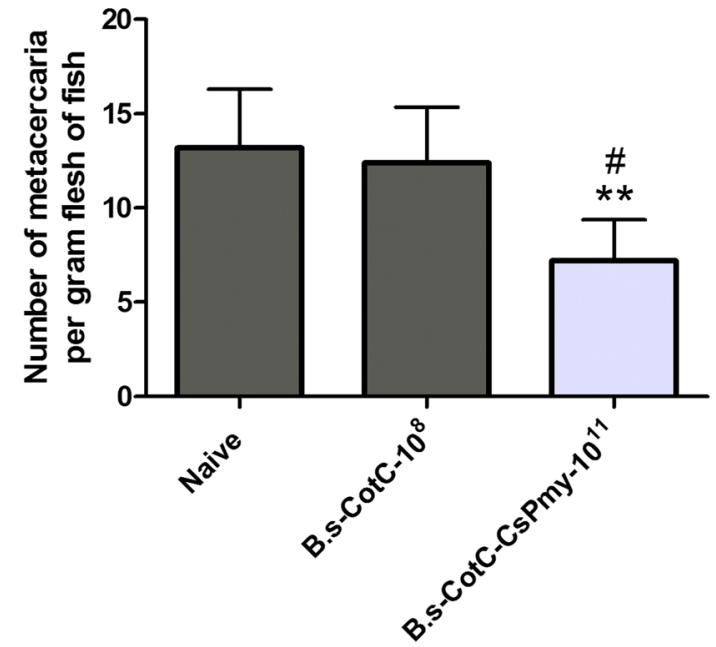

The specific IgM levels in the intestinal mucus and bile of grass carp increased more early than that in sera or skin mucus in B.s-CotC-CsPmy groups (Fig. 2). It might due to that orally delivered antigen (CsPmy) interacted with the local immune system on the intestinal mucosa first and later triggered the systemic immune reaction.

It has been documented that immune status of grass carp was closely related to expression of cytokines (Secombes et al. 2001). IL-8 was considered to be one of the most important proinflammatory cytokines in grass carp (Wang et al. 2013). IL-8 expresses in immune-related tissues in grass carp such as the head kidney, spleen, gill, and so on. IL-8 level would increase when grass carp was stimulated by heterologous antigens or pathogens resulting in attraction of other immunerelated cells for fighting against the pathogens (Wang et al. 2013). TNF- $\alpha$ was also proved to be a crucial cytokine involved in immune regulation and mediates the inflammatory responses in grass carp (Zhang et al. 2012; Zhu et al. 2013). In the current study, mRNA levels of TNF- $\alpha$ and IL- 8 in the head kidney and spleen in B.s-CotC-CsPmy- $10^{8}$ and $10^{11}$ groups were significantly up-regulated at week 6 (Fig. S1). It demonstrated that oral administration of the recombinant spores activated the innate immunity and might invoke specific adaptive immune responses (Liu et al. 2015). Additionally, the TNF- $\alpha$ level had no significant difference in B.s-CotC-
CsPmy $1 \times 10^{5}$ and $1 \times 10^{8}$ group in the head kidney. The possible reason might be that the spore dosages $\left(1 \times 10^{5}\right.$ and $1 \times 10^{8} \mathrm{CFU} / \mathrm{g}$ ) were not enough to induce TNF- $\alpha$ secretion in the head kidney because a certain amount of the spores might be excreted from the intestine with the intestinal movement (Leser et al. 2008).

Studies showed that the structural integrity of intestinal mucosa was crucial to vaccinated fishes (Feng et al. 2015). Tight junction proteins play vital roles in tight junction among epithelial cells of intestine which maintains intestinal integrity resulting in the foundation of mechanical barrier (Chen et al. 2015). Evidences indicated that expressions of tight junction proteins such as ZO-1, occludin, claudin $\mathrm{b}$, or claudin $\mathrm{c}$ would be down-regulated when intestinal mucosa was damaged by inflammation (Chen et al. 2015; Feng et al. 2015; Gong et al. 2016). Our results showed that oral administration with $10^{8}$ or $10^{11} \mathrm{CFU} / \mathrm{g}^{-}$B. subtilis spores up-regulated mRNA levels of occludin, claudin $b$, and claudin $\mathrm{c}$ in foregut, midgut, and hindgut. mRNA levels of ZO-1 increased in the foregut (Fig. S2). It was previously mentioned that $B$. subtilis could promote epithelial tight junctions of mice with inflammatory bowel disease (Gong et al. 2016), indicating that $B$. subtilis spores were beneficial to maintenance of structural integrity of intestinal mucosa in grass carp. 
The gastrointestinal microflora is a complex ecosystem harboring a variety of bacterial communities and plays an imperative role in immune regulation and nutrition consumption of the host (Han et al. 2010; Hao et al. 2017a; Hao et al. 2017b). Variation in the diversity and abundance of bacteria in intestine seriously impairs the immune development and function (Nayak 2010). It has been verified that probiotic additive (e.g., B. subtilis) enhance certain innate immune response, thus improve disease resistance of the host (Hao et al. 2017a; Li et al. 2016; Liu et al. 2015). In addition, probiotic supplement in the diets improves growth performance by positively improving the composition of intestinal microbial community (Hao et al. 2017a).

We analyzed intestinal microbiota by using $16 \mathrm{~S}$ rRNA sequencing. Our results indicated that Proteobacteria, Firmicutes, and Fusobacteria were the dominant phyla in each group (Table 1), suggesting that dietary supplement of B. subtilis spores did not affect the primary phyla constitution of grass carp. Compared with naïve group, both the diversity and richness indices of bacteria in intestines of spores administrated grass carp were elevated, especially in B.s-CotCCsPmy- $10^{11}$ group. The results of PCA, Venn, and heatmap also verified that the intestinal microbiota in B.s-CotCCsPmy- $10^{11}$ group was dramatically different from the other groups (Fig. 4).

Previous studies reported that $B$. subtilis $\mathrm{Ch} 9$ and B. subtilis CGMCC 1.1086 strains could increase probiotics but decrease pathogenetic bacteria in intestinal of grass carp or broilers (Hao et al. 2017a; Li et al. 2016). Streptococcus, Lactobacillus, and Micrococcus have been widely used as probiotics in aquaculture and brought positive effects on the host including improvement of the immune status and inhibiting pathogen infection in the intestines (Balcazar et al. 2006; Hai 2015). In our present study, the abundance of Streptococcus and Lactobacillus in high-dosage spores-treated group was dramatically higher than those in other groups (Table 2), while Lactobacillus was not detected in intestine of $B$. subtilis treated fish (Hao et al. 2017a). Considering that culture condition and feed may affect intestinal microbiota of fish (Han et al. 2010; Wu et al. 2012), it might due to the different culture condition and diet in different experiments.

Some strains from Flavobacterium and Pseudomonas genera were considered to be potential pathogens to grass carp, as they might induce columnaris disease, white head-mouth disease, and red skin disease (Hao et al. 2017a). Lower abundance of Flavobacterium was found in naïve group but not in B. subtilis treated groups. Dramatically lower abundance of Pseudomonas in B.s-CotC-CsPmy-10 ${ }^{11}$ group was detected compared with Naïve group (Table 2). The results demonstrated that oral administration with probiotics might reduce potential pathogenic bacteria in grass carp intestine (Hao et al. 2017a; Liu et al. 2015). A possible explanation might be that probiotics generate antibiotics, bacteriocins, hydrogen peroxide, and lysozyme, etc., thus inhibit the adherence or proliferation of pathogens in intestinal mucosa (Hai 2015; Sugita et al. 1998).

In addition, Rikenellaceae, Ruminococcaceae, and Lachnospiraceae were dramatically increased in B.s-CotCCsPmy- $10^{11}$ group. At genus level, higher abundance of Alistipes, Odoribacter, and Desulfovibrio in the high-dosage group were presented (Table 3). Rikenellaceae were considered as intestine beneficial bacteria, as Alistipes genus belong to the family can produce fibrinolysin, digest gelatin, and ferment carbohydrate resulting in enhancement of digestion in fishes(Li et al. 2016). Odoribacter can produce short-chain fatty acids (SCFAs) such as acetic acid, succinic acid, or butyric acid, which are beneficial to both microbial and epithelial cell growth of host (Meehan and Beiko 2014). Desulfovibrio has also been proved to be beneficial to the microbial community and able to improve energy recovery from food ( $\mathrm{Li}$ et al. 2016). Lachnospiraceae are a butyrate-producing superfamily, which can produce an enzyme to break down a wide variety of complex carbohydrates found in plants (Hao et al. 2017b). Hence, higher abundances of these bacteria found in the intestines would probably be helpful to digestion function of grass carp and promote their growth performance.

Compared with naïve group, abundances of bacteria mentioned above were not obviously changed in $\mathrm{BC}, \mathrm{BL}$, and $\mathrm{BM}$ group (B.s-CotC- $10^{8}$, B.s-CotC- CsPmy- $10^{5} / 10^{8}$ groups) (Tables 1, 2, 3). It might because that lower dosage of B. subtilis spores accompanied by less colonized B. subtilis spores in intestine of grass carp (Hao et al. 2017a).

After oral immunization, the fishes were infected with C. sinensis cercaria for a week. Compared with naïve group, metacercaria intensities in B.s-CotC-CsPmy- $10^{11}$ spore treated grass carp were significantly decreased (Fig. 5C). We conjectured that immune responses induced by the recombinant spores (B.s-CotC-CsPmy) played roles in protecting against adherence or invasion of cercaria to grass carp. It needed further study to illuminate the involved mechanisms. When grass carp was orally administrated with B.s-CotCCSCP spore $\left(10^{7}\right.$ dosages), no metacercariae were observed (Tang et al. 2017). We speculated that might be due to two reasons: firstly, the function and immunogenicity of CsPmy were different from those of CsCP (Tang et al. 2016a; Wang et al. 2012) resulting in different protect effect. Secondly, the methods used for metacercariae detection were different. In the former study, metacercariae were checked by direct compression method by randomly picking fish flesh from 5 different positions in one fish (Tang et al. 2017), which might lead to missed detection when the infection intensity was low. While in our present study, we checked by digestion method with high detection rate. That is, the fishes were totally digested with artificial gastric juice, so that every metacercariae could be detected. 
In conclusion, oral administration with B.s-CotC-CsPmy spores could induced both systemic and local mucosal immune responses without bad effects on intestinal structural integrity and elicited promising protective effect in grass carp. Additionally, oral treatment of the spores in grass carp could reduce the abundance of potentially pathogenic bacteria (e.g., Flavobacterium) and enhance the abundance of probiotics (e.g., Streptococcus, Lactobacillus) or bacteria associated with digestion. Our work suggested that $B$. subtilis spore presenting CsPmy on the surface is a promising effect, safe, and needlefree oral vaccine candidate for prevention of $C$. sinensis infection in grass carp. Our study established the cornerstone for the prevention of $C$. sinensis infection in both human and mammalian reservoir hosts by using fish vaccine to cut off its life cycle. This work also shed light on the vaccine development for other zoonosis.

Funding information This study was funded by the national key research and development program of China (2017YFD0501300), Guangdong marine economy promotion projects fund (GDOE[2019]A29), and the science and technology planning project of Guangdong province (No.2014B020203001).

\section{Compliance with ethical standards}

Conflict of interest The authors declares that they have no conflict of interest.

Ethical approval All applicable international, national, and/or institutional guidelines for the care and use of animals were followed.

\section{References}

Abou-Elhakam H, Rabee I, El Deeb S, El Amir A (2013) Protection against Fasciola gigantica using paramyosin antigen as a candidate for vaccine production. Pak J Biol Sci 16(22):1449-1458

Balcazar JL, de Blas I, Ruiz-Zarzuela I, Cunningham D, Vendrell D, Muzquiz JL (2006) The role of probiotics in aquaculture. Vet Microbiol 114(3-4):173-186. https://doi.org/10.1016/j.vetmic. 2006.01.009

Caporaso JG, Kuczynski J, Stombaugh J, Bittinger K, Bushman FD, Costello EK, Fierer N, Pena AG, Goodrich JK, Gordon JI, Huttley GA, Kelley ST, Knights D, Koenig JE, Ley RE, Lozupone CA, McDonald D, Muegge BD, Pirrung M, Reeder J, Sevinsky JR, Turnbaugh PJ, Walters WA, Widmann J, Yatsunenko T, Zaneveld J, Knight R (2010) QIIME allows analysis of high-throughput community sequencing data. Nat Methods 7(5):335-336. https://doi.org/ 10.1038/nmeth.f.303

Chen L, Feng L, Jiang WD, Jiang J, Wu P, Zhao J, Kuang SY, Tang L, Tang WN, Zhang YA, Zhou XQ, Liu Y (2015) Intestinal immune function, antioxidant status and tight junction proteins mRNA expression in young grass carp (Ctenopharyngodon idella) fed riboflavin deficient diet. Fish Shellfish Immun 47(1):470 484. https://doi.org/10.1016/j.fsi.2015.09.037

Duc le H, Hong HA, Cutting SM (2003) Germination of the spore in the gastrointestinal tract provides a novel route for heterologous antigen delivery. Vaccine 21(27-30):4215-4224
Edgar RC, Haas BJ, Clemente JC, Quince C, Knight R (2011) UCHIME improves sensitivity and speed of chimera detection. Bioinformatics 27(16):2194-2200. https://doi.org/10.1093/bioinformatics/btr381

Fang F, Li J, Huang T, Guillot J, Huang W (2015) Zoonotic helminths parasites in the digestive tract of feral dogs and cats in Guangxi, China. BMC Vet Res 11(1):211

Feng L, Li W, Liu Y, Jiang WD, Kuang SY, Jiang J, Tang L, Wu P, Tang WN, Zhang YA, Zhou XQ (2015) Dietary phenylalanine-improved intestinal barrier health in young grass carp (Ctenopharyngodon idella) is associated with increased immune status and regulated gene expression of cytokines, tight junction proteins, antioxidant enzymes and related signalling molecules. Fish Shellfish Immun 45(2):495-509. https://doi.org/10.1016/j.fsi.2015.05.001

Fu LL, Shuai JB, Xu ZR, Li JR, Li WF (2010) Immune responses of Fenneropenaeus chinensis against white spot syndrome virus after oral delivery of VP28 using Bacillus subtilis as vehicles. Fish Shellfish Immun 28(1):49-55. https://doi.org/10.1016/j.fsi.2009.09.016

Gong Y, Li H, Li Y (2016) Effects of Bacillus subtilis on epithelial tight junctions of mice with inflammatory bowel disease. J Interf Cytokine Res 36(2):75-85

Gudding R, Van Muiswinkel WB (2013) A history of fish vaccination: science-based disease prevention in aquaculture. Fish Shellfish Immun 35(6):1683-1688. https://doi.org/10.1016/j.fsi.2013.09.031

Guo X, Chen DD, Peng KS, Cui ZW, Zhang XJ, Li S, Zhang YA (2016) Identification and characterization of Bacillus subtilis from grass carp (Ctenopharynodon idellus) for use as probiotic additives in aquatic feed. Fish Shellfish Immun 52:74-84. https://doi.org/10. 1016/j.fsi.2016.03.017

Hai NV (2015) The use of probiotics in aquaculture. J Appl Microbiol 119(4):917-935. https://doi.org/10.1111/jam.12886

Han S, Liu Y, Zhou Z, He S, Cao Y, Shi P, Yao B, RingÖ E (2010) Analysis of bacterial diversity in the intestine of grass carp (Ctenopharyngodon idellus) based on 16S rDNA gene sequences. Aquac Res 42(1):47-56

Hao K, Wu ZQ, Li DL, Yu XB, Wang GX, Ling F (2017a) Effects of dietary administration of Shewanella xiamenensis A-1, Aeromonas veronii $\mathrm{A}-7$, and Bacillus subtilis, single or combined, on the grass carp (Ctenopharyngodon idella) intestinal microbiota. Probiotics Antimicro 9:386-396. https://doi.org/10.1007/s12602-017-9269-7

Hao YT, Wu SG, Jakovlić I, Zou H, Li WX, Wang GT (2017b) Impacts of diet on hindgut microbiota and short-chain fatty acids in grass carp (Ctenopharyngodon idellus). Aquac Res 48(11):5595-5605. https://doi.org/10.1111/are.13381

Huang Y, Huang D, Geng Y, Fang S, Yang F, Wu C, Zhang H, Wang M, Zhang R, Wang X, Wu S, Cao J, Zhang R (2017) An integrated control strategy takes Clonorchis sinensis under control in an endemic area in South China. Vector Borne Zoonot. https://doi.org/10.1089/vbz.2017.2133

Jiang H, Chen T, Sun H, Tang Z, Yu J, Lin Z, Ren P, Zhou X, Huang Y, Li $X$, Yu X (2017) Immune response induced by oral delivery of Bacillus subtilis spores expressing enolase of Clonorchis sinensis in grass carps (Ctenopharyngodon idellus). Fish Shellfish Immun 60:318-325. https://doi.org/10.1016/j.fsi.2016.10.011

Jiz MA, Wu H, Olveda R, Jarilla B, Kurtis JD (2015) Development of Paramyosin as a vaccine candidate for schistosomiasis. Front Immunol 6:347. https://doi.org/10.3389/fimmu.2015.00347

Katayama H, Nagasu T, Oda Y (2001) Improvement of in-gel digestion protocol for peptide mass fingerprinting by matrix-assisted laser desorption/ionization time-of-flight mass spectrometry. Rapid Commun Mass Spectrom 15(16):1416-1421. https://doi.org/10.1002/rcm.379

Lai DH, Hong XK, Su BX, Liang C, Hide G, Zhang X, Yu X, Lun ZR (2016) Current status of Clonorchis sinensis and clonorchiasis in China. Trans R Soc Trop Med Hyg 110(1):21-27. https://doi.org/ $10.1093 /$ trstmh/trv100 
Leser TD, Knarreborg A, Worm J (2008) Germination and outgrowth of Bacillus subtilis and Bacillus licheniformis spores in the gastrointestinal tract of pigs. J Appl Microbiol 104(4):1025-1033. https://doi. org/10.1111/j.1365-2672.2007.03633.x

Li Y, Xu Q, Huang Z, Lv L, Liu X, Yin C, Yan H, Yuan J (2016) Effect of Bacillus subtilis CGMCC 1.1086 on the growth performance and intestinal microbiota of broilers. J Appl Microbiol 120(1):195-204. https://doi.org/10.1111/jam.12972

Liang C, Hu XC, Lv ZY, Wu ZD, Yu XB, Xu J, Zheng HQ (2009) Experimental establishment of life cycle of Clonorchis sinensis. Zhongguo Ji Sheng Chong Xue Yu Ji Sheng Chong Bing Za Zhi 27(2):148-150

Lin RQ, Tang JD, Zhou DH, Song HQ, Huang SY, Chen JX, Chen MX, Zhang H, Zhu XQ, Zhou XN (2011) Prevalence of Clonorchis sinensis infection in dogs and cats in subtropical southern China. Parasit Vectors 4 (1): 180

Liu L, Gong YX, Zhu B, Liu GL, Wang GX, Ling F (2015) Effect of a new recombinant Aeromonas hydrophila vaccine on the grass carp intestinal microbiota and correlations with immunological responses. Fish Shellfish Immun 45(1):175-183. https://doi.org/10. 1016/j.fsi.2015.03.043

Liu H, Wang S, Cai Y, Guo X, Cao Z, Zhang Y, Liu S, Yuan W, Zhu W, Zheng Y, Xie Z, Guo W, Zhou Y (2017) Dietary administration of Bacillus subtilis HAINUP40 enhances growth, digestive enzyme activities, innate immune responses and disease resistance of tilapia, Oreochromis niloticus. Fish Shellfish Immun 60:326333. https://doi.org/10.1016/j.fsi.2016.12.003

Lun Z-R, Gasser RB, Lai D-H, Li A-X, Zhu X-Q, Yu X-B, Fang Y-Y (2005) Clonorchiasis: a key foodborne zoonosis in China. Lancet Infect Dis 5(1):31-41

Machicado C, Marcos LA (2016) Carcinogenesis associated with parasites other than Schistosoma, Opisthorchis and Clonorchis: a systematic review. Int J Cancer 138(12):2915-2921. https://doi.org/10. 1002/ijc. 30028

Meehan CJ, Beiko RG (2014) A phylogenomic view of ecological specialization in the Lachnospiraceae, a family of digestive tractassociated bacteria. Genome Biol Evol 6(3):703-713. https://doi. org/10.1093/gbe/evu050

Nayak SK (2010) Role of gastrointestinal microbiota in fish. Aquac Res 41(11):1553-1573. https://doi.org/10.1111/j.13652109.2010.02546.x

Nguyen HM, Tatonova YV, Madsen H (2018) Infections by hepatic trematodes in cats from slaughterhouses in Vietnam. J Parasitol 104(3): 306-310

Nicholson WLSP (1990) Sporulation, germination and outgrowth. In: HarwoodCR CSM (ed) Molecular biological methods for Bacillus. Wiley, Chichester, pp 391-450

Plant KP, Lapatra SE (2011) Advances in fish vaccine delivery. Dev Comp Immunol 35(12):1256-1262. https://doi.org/10.1016/j.dci. 2011.03.007

Qian MB, Utzinger J, Keiser J, Zhou XN (2016) Clonorchiasis. Lancet 387(10020):800-810. https://doi.org/10.1016/s0140-6736(15) 60313-0

Quentel C, Vigneulle M (1997) Antigen uptake and immune responses after oral vaccination. Dev Biol Stand 90:69-78

Ricca E, Baccigalupi L, Cangiano G, De Felice M, Isticato R (2014) Mucosal vaccine delivery by non-recombinant spores of Bacillus subtilis. Microb Cell Factories 13:115. https://doi.org/10.1186/ s12934-014-0115-2

Rosales-Mendoza S, Angulo C (2015) Bacillus subtilis comes of age as a vaccine production host and delivery vehicle. Expert Rev Vaccines 14(8):1135-1148. https://doi.org/10.1586/14760584.2015.1051469

Salinas I (2015) The mucosal immune system of teleost fish. Biology (Basel) 4(3):525-539. https://doi.org/10.3390/biology4030525

Sanchez-Ortiz AC, Angulo C, Luna-Gonzalez A, Alvarez-Ruiz P, Mazon-Suastegui JM, Campa-Cordova AI (2016) Effect of mixed-
Bacillus spp isolated from pustulose ark Anadara tuberculosa on growth, survival, viral prevalence and immune-related gene expression in shrimp Litopenaeus vannamei. Fish Shellfish Immun 59:95102. https://doi.org/10.1016/j.fsi.2016.10.022

Secombes CJ, Wang T, Hong S, Peddie S, Crampe M, Laing KJ, Cunningham C, Zou J (2001) Cytokines and innate immunity of fish. Dev Comp Immunol 25(8-9):713-723

Sugita H, Hirose Y, Matsuo N, Deguchi Y (1998) Production of the antibacterial substance by Bacillus sp. strain NM 12, an intestinal bacterium of Japanese coastal fish. Aquaculture 165(3):269-280. https://doi.org/10.1016/S0044-8486(98)00267-1

Sun $\mathrm{H}$, Lin Z, Zhao L, Chen T, Shang M, Jiang H, Tang Z, Zhou X, Shi M, Zhou L (2018) Bacillus subtilis spore with surface display of paramyosin from Clonorchis sinensis potentializes a promising oral vaccine candidate. Parasit Vectors 11(1):156

Tang Z, Shang M, Chen T, Ren P, Sun H, Qu H, Lin Z, Zhou L, Yu J, Jiang H, Zhou X, Li X, Huang Y, Xu J, Yu X (2016a) The immunological characteristics and probiotic function of recombinant Bacillus subtilis spore expressing Clonorchis sinensis cysteine protease. Parasit Vectors 9(1):648. https:// doi.org/10.1186/s13071-016-1928-0

Tang ZL, Huang Y, Yu XB (2016b) Current status and perspectives of Clonorchis sinensis and clonorchiasis: epidemiology, pathogenesis, omics, prevention and control. Infect Dis Poverty 5(1):71. https://doi.org/10.1186/s40249-016-0166-1

Tang Z, Sun H, Chen T, Lin Z, Jiang H, Zhou X, Shi C, Pan H, Chang O, Ren P, Yu J, Li X, Xu J, Huang Y, Yu X (2017) Oral delivery of Bacillus subtilis spores expressing cysteine protease of Clonorchis sinensis to grass carp (Ctenopharyngodon idellus): induces immune responses and has no damage on liver and intestine function. Fish Shellfish Immun 64:287296. https://doi.org/10.1016/j.fsi.2017.03.030

Tavares Batista M, Souza RD, Paccez JD, Luiz WB, Ferreira EL, Cavalcante RC, Ferreira RC, Ferreira LC (2014) Gut adhesive Bacillus subtilis spores as a platform for mucosal delivery of antigens. Infect Immun 82(4):1414-1423. https://doi.org/10.1128/IAI. 01255-13

Truong Thy HT, Tri NN, Quy OM, Fotedar R, Kannika K, Unajak S, Areechon N (2017) Effects of the dietary supplementation of mixed probiotic spores of Bacillus amyloliquefaciens 54A, and Bacillus pumilus $47 B$ on growth, innate immunity and stress responses of striped catfish (Pangasianodon hypophthalmus). Fish Shellfish Immun 60:391-399. https://doi.org/10.1016/j. fsi.2016.11.016

Valdez A, Yepiz-Plascencia G, Ricca E, Olmos J (2014) First Litopenaeus vannamei WSSV $100 \%$ oral vaccination protection using CotC::Vp26 fusion protein displayed on Bacillus subtilis spores surface. J Appl Microbiol 117(2):347-357. https://doi.org/10.1111/jam.12550

Vazquez-Talavera J, Solis CF, Terrazas LI, Laclette JP (2001) Characterization and protective potential of the immune response to Taenia solium paramyosin in a murine model of cysticercosis. Infect Immun 69(9):5412-5416

Wang GX, Liu YT, Li FY, Gao HT, Lei Y, Liu XL (2010) Immunostimulatory activities of Bacillus simplex DR-834 to carp (Cyprinus carpio). Fish Shellfish Immun 29(3):378387. https://doi.org/10.1016/j.fsi.2010.03.014

Wang X, Chen W, Lv X, Tian Y, Men J, Zhang X, Lei H, Zhou C, Lu F, Liang C, Hu X, Xu J, Wu Z, Li X, Yu X (2012) Identification and characterization of paramyosin from cyst wall of metacercariae implicated protective efficacy against Clonorchis sinensis infection. PLoS One 7(3):e33703. https://doi.org/10.1371/journal.pone. 0033703

Wang TT, Song XH, Bao GM, Zhao LX, Yu X, Zhao J (2013) Molecular characterization, expression analysis, and biological effects of 
interleukin-8 in grass carp Ctenopharyngodon idellus. Fish Shellfish Immun 35(5):1421-1432. https://doi.org/10.1016/j.fsi.2013.08.006

Wu S, Wang G, Angert ER, Wang W, Li W, Zou H (2012) Composition, diversity, and origin of the bacterial community in grass carp intestine. PLoS One 7(2):e30440. https://doi. org/10.1371/journal.pone.0030440

Xu Z, Parra D, Gomez D, Salinas I, Zhang YA, von Gersdorff JL, Heinecke RD, Buchmann K, LaPatra S, Sunyer JO (2013) Teleost skin, an ancient mucosal surface that elicits gut-like immune responses. Proc Natl Acad Sci U S A 110(32): 13097-13102. https://doi.org/10.1073/pnas. 1304319110

Zhang A, Chen D, Wei H, Du L, Zhao T, Wang X, Zhou H (2012) Functional characterization of TNF-alpha in grass carp head kidney leukocytes: induction and involvement in the regulation of NFkappaB signaling. Fish Shellfish Immun 33(5):1123-1132. https:// doi.org/10.1016/j.fsi.2012.08.029
Zheng S, Zhu Y, Zhao Z, Wu Z, Okanurak K, Lv Z (2017) Liver fluke infection and cholangiocarcinoma: a review. Parasitol Res 116(1): 11-19. https://doi.org/10.1007/s00436-016-5276-y

Zhou Z, Xia H, Hu X, Huang Y, Li Y, Li L, Ma C, Chen X, Hu F, Xu J, Lu F, Wu Z, Yu X (2008) Oral administration of a Bacillus subtilis sporebased vaccine expressing Clonorchis sinensis tegumental protein $22.3 \mathrm{kDa}$ confers protection against Clonorchis sinensis. Vaccine 26(15):1817-1825. https://doi.org/10.1016/j.vaccine.2008.02.015

Zhu LY, Nie L, Zhu G, Xiang LX, Shao JZ (2013) Advances in research of fish immune-relevant genes: a comparative overview of innate and adaptive immunity in teleosts. Dev Comp Immunol 39(1-2): 39-62. https://doi.org/10.1016/j.dci.2012.04.001

Publisher's note Springer Nature remains neutral with regard to jurisdictional claims in published maps and institutional affiliations. 